УДК 621.867.133, DOI 10.31210/visnyk2018.04.31

(C) 2018

Бурлака О. А., кандидат технічних наук,

Яхін С. В., кандидат технічних наук

Полтавська державна аграрна академія

\title{
ПІДВИЩЕННЯ ЕФЕКТИВНОСТІ РОБОТИ СКРЕБКОВИХ ЕЛЕВАТОРІВ З ВІДЦЕНТРОВИМ ТИПОМ РОЗВАНТАЖЕННЯ
}

\section{Рецензент - доктор технічних наук, професор В. П. Дмітриков}

Підвищені енергетичні витрати на транспортування, висока ступінь подрібнення зерна пов'язані $з$ наявними недоліками існуючих конструкиій скребкових елеваторів з відиентровим типом розвантаження, $\epsilon$ зворотне осипання (колова ичиркуляція) зерна. Для усунення цього недоліку необхідно проаналізувати фактори, щчо впливають на напрямок потоку вантажу залежно від його швидкості та положення натяжного пристрою. За результатами експериментальних досліджень ефективності роботи скребкових елеваторів встановлено залежність зворотного сипу зерна в елеваторі (колової цииккляції) від швидкості транспортування та сектору розвантаження. Запропоновано враховувати особливості роботи натяжного механізму скребкового елеватору на зернозбиральних комбайнах та дообладнати верхню частину елеватора додатковим направляючим кожухом.

Ключові слова: елеватор, зерновий потік, подрібнення зерна, сектор розвантаження, колова ичиркулячія.

Постановка проблеми. Якість транспортування зерна скребковими елеваторами 3 відцентровим типом розвантаження, що використовуються на значній частині моделей зернозбиральних комбайнів вітчизняного та закордонного виробництва, а також в транспортних лініях зернопереробного обладнання - силосах, шахтах, очисних та сушильних зернових комплексах, зернопереробних лініях, не повністю відповідає сучасним вимогам. Внаслідок виявленої недосконалості конструкції головки елеватора, що поєднана 3 натяжним пристроєм, під час транспортування зернових спостерігається зворотне осипання та, відповідно, подрібнення частини вантажу скребками, ланцюгом та зірочками елеватора.

Аналіз основних досліджень і публікацій, у яких запропоновано розв'язання проблеми. Проблемам теорії та практики щодо удосконалення транспортних систем сільськогосподарських машин присвятили частину своїх досліджень відомі вітчизняні та закордонні вчені, наприклад Погорілий Л. В., Сакун В. А., Листопад Г. Е., Босой Е. С. та ін. Однак питання підвищення якості транспортування зерна скребковими елеваторами з відцентровим типом розвантаження потребують подальшого вдосконалення, тому на них і зосереджено головну увагу даного дослідження.

Мета досліджень: розробка заходів та рекомендацій по зменшенню зворотного осипання (колової циркуляції) зерна в разі відцентрового розвантаження та зменшенню пошкоджень зерна робочими органами скребкового елеватора, що $\epsilon$ актуальною проблемою в складі модернізації галузевого машинобудування, тому дослідження процесу транспортування зерна дає змогу вжити заходів для підвищення якості роботи транспортних систем зернової групи сільськогосподарських машин.

Матеріали і методи досліджень. Для встановлення факторів, що впливають на продуктивність розвантаження зерна скребковим елеватором, проведено експериментальні дослідження на спеціально розробленій установці $[1,2,3]$ та використано методи математичного моделювання процесу розвантаження.

Результати досліджень. Процес транспортування порції зерна скребковим елеватором можна розділити на чотири частини за умовами та видом руху динамічної системи.

Перша частина - прямолінійний рівномірний рух під час підйому зерна до верхньої головки елеватора (дестабілізуючі фактори не враховуються).

Друга частина - складний рух порції зерна у верхній головці елеватора до початку розвантаження (перерозподіл зернової маси в зоні, що обмежена кожухом транспортера): переносний рух шарів зерна під дією скребка, як обертальний рух навколо осі верхньої приводної зірочки та відносний рух зерна по скребку під дією відцентрових сил до обмеження кожухом.

Третя частина - рух шарів зерна на початку відцентрового розвантаження як відносний рух по скребку елеватора.

Четверта частина - рух шарів зерна під час відцентрового розвантаження після відриву від 
скребка по настильній траєкторії у вільному об'ємі перевантажувальної камери зерно-транспортної лінії молотарки.

Розглянемо більш детально третю та четверту частину технологічного процесу i транспортування - відносний рух порції зерна по скребку елеватора під час обертання останнього навколо повздовжньої осі симетрії валу ведучої верхньої зірочки ланцюгової передачі та відрив шарів зерна під переважаючою дією відцентрової сили (рис. 1, рис. 2).

На зернину або порцію зерна відносно скребка у верхній голівці елеватора в разі відцентрового типу розвантаження та розташуванні скребка під кутом $\psi$ до радіуса обертання діють сили (рис.1): $G=m g$ - вага зернини; $N$-нормальна реакція поверхні; $F=k N$ - сила тертя зернини по поверхні скребка; $P_{u н}=m r^{2}$ - відцентрова сила інерції; $F_{n о в}=k m v$ - сила опору повітря, що виникає під час руху матеріальної точки відносно скребка та діє в напрямку, протилежному такому рухові; $F_{\text {кар }}=2 m v$ - сила Каріоліса, спрямована перпендикулярно до вектору відносної швидко- сті та діюча в напрямку, протилежному напрямку обертання. При цьому домінуючою $є$ сила інерції, яка і формує процес відцентрового розвантаження скребкового елеватора.

Якщо охарактеризувати процес руху зерна у верхній частині скребкового елеватора під переважною дією відцентрової сили, то спочатку остання сила примушує рухатись шари зерна від центру обертання по поверхні скребка (рис. 2, поз. 5) до зовнішнього радіусу обертання. Відрив шарів зерна від поверхні скребка відбувається на його зовнішній верхній кромці, при цьому шари зерна вилітають по нормалі до поверхні скребка (рис. 2, поз. 4). Коригування траєкторії вильоту зернового потоку здійснюється кришкою верхньої частини елеватора (рис. 2, поз. 6 та рис. 3 , поз 1.). Якщо час руху зерна по поверхні скребка елеватора рівний, або менший часу обертання скребка під час проходження зони розвантаження (рис. 2), то маємо високу імовірність попадання шарів зернового потоку в межі кута $\alpha$ (рис. 2), при цьому відцентрове розвантаження пройде успішно.

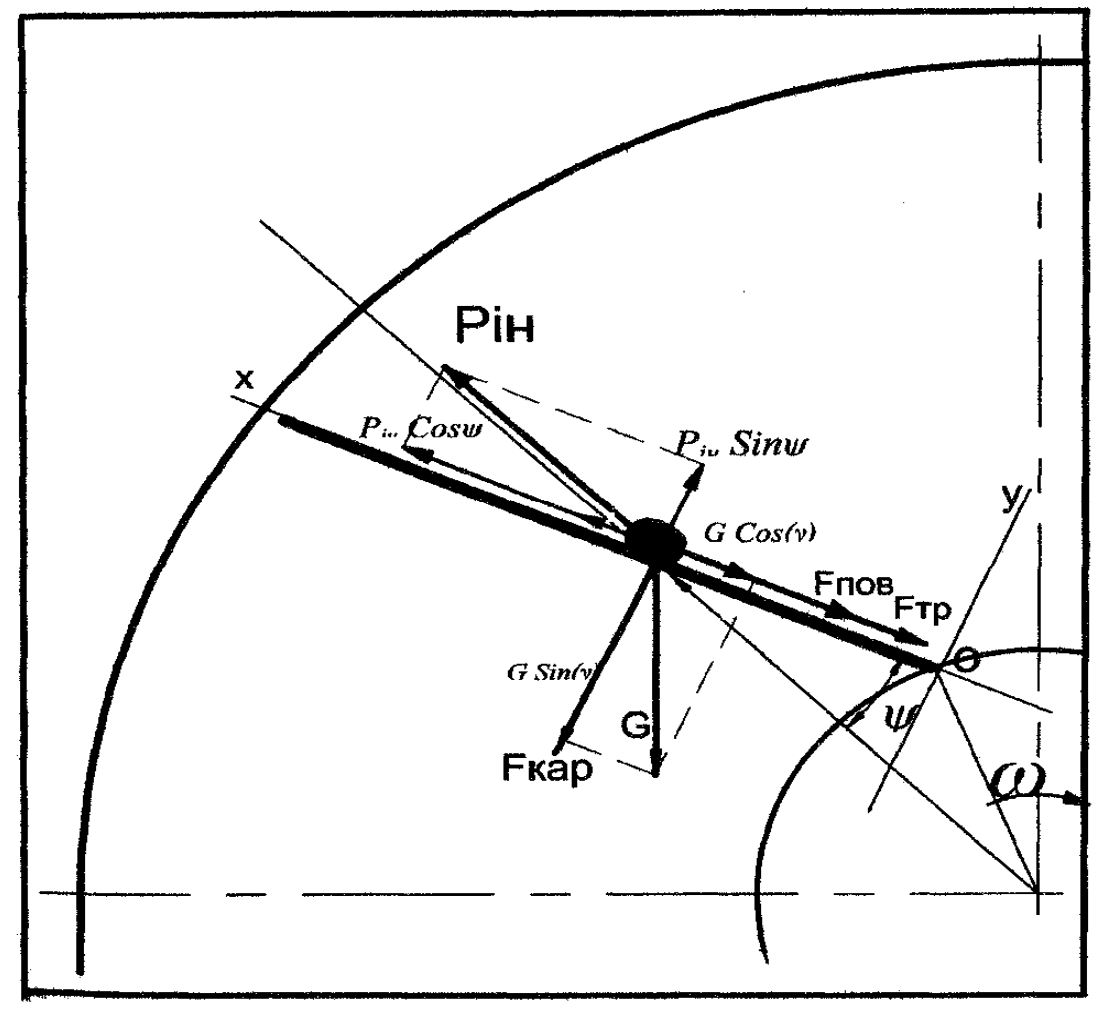

Рис. 1. Схема сил, що діють на зерно або порцію зерна відносно скребка у верхній голівці елеватора за віцентрового типу розвантаження та розташуванні скребка під кутом $\psi$ до радіуса обертання 


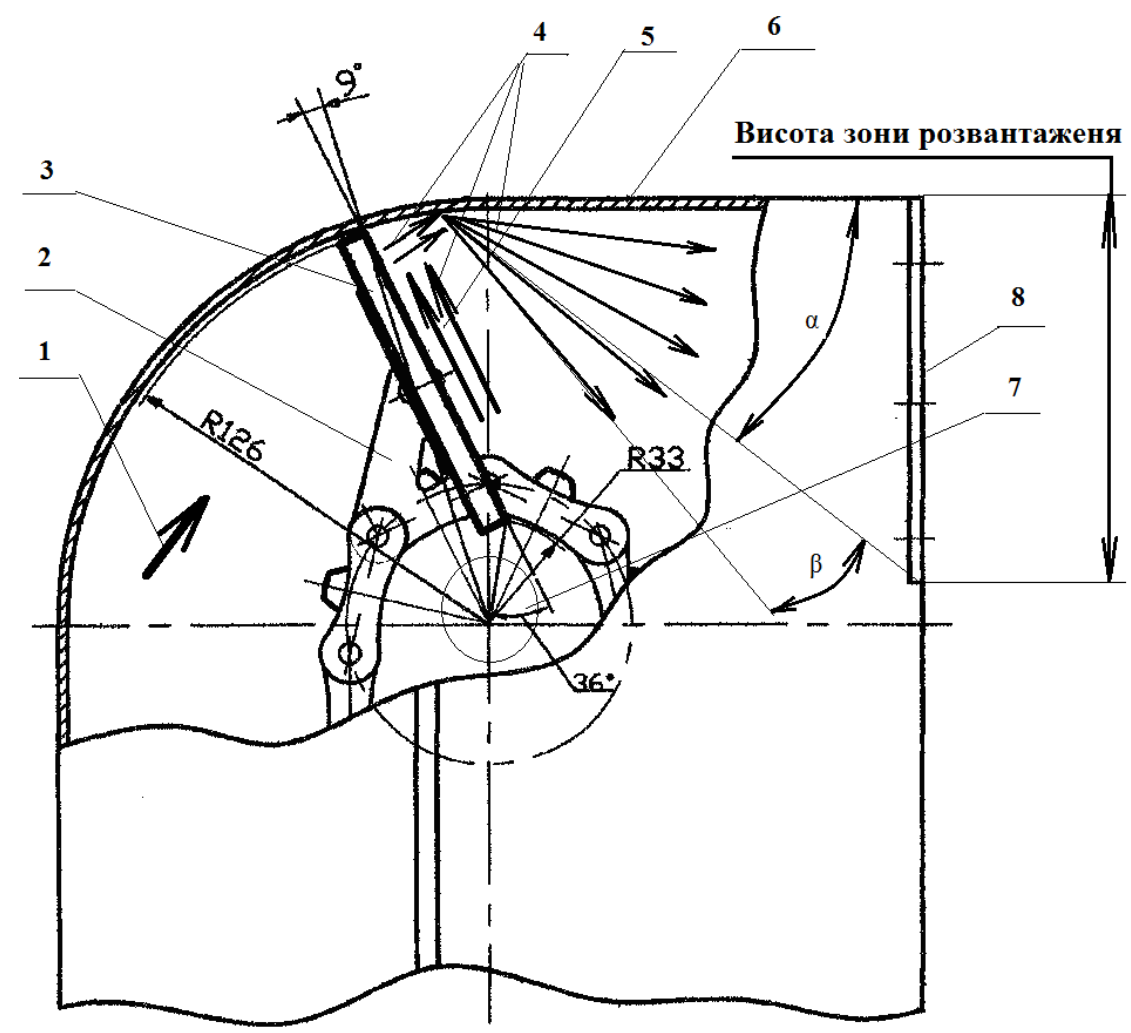

\section{Рис. 2. Схема верхньої частини скребкового елеватора зернозбирального комбайна типу «КЗС-9-1» «Славутич», «Дон», «Вектор», «Акрос»}

1 - напрям руху зернового потоку; 2 - фрагмент ланцюга елеватора зі скребком; 3 - скребок; 4 - імовірні напрями руху шарів зернового потоку у верхній частині елеватора під час здійснення відцентрового розвантаження; 5 - напрям руху шарів зерна по поверхні скребка елеватора;

6 - кришка верхньої частини зернового елеватора; 7 - верхній привідний вал з зірочкою приводу ланцюга зі скребками; $\alpha$ - кут, що утворює сектор розвантаження; $\beta$ - кут зворотного осипання зерна.

Якщо траєкторія вильоту зернових прошарків попаде в зону кута $\beta$, то маємо потрапляння зерна в холосту частину скребкового елеватора, тобто утворюється зворотній сип - колова циркуляція зерна в кожусі елеватора. Таке явище $\epsilon$ досить негативним, так як спричиняє додаткові енергетичні витрати на транспортування, збільшує подрібнення та компресійне пошкодження зернової маси, пришвидшує знос робочих органів зернової транспортної системи комбайна.

Більш детально розглянемо будову верхньої частини скребкового елеватора сучасних зернозбиральних комбайнів типу «КЗС-9-1» «Славутич», «Дон», «Вектор», «Акрос» (рис. 3).

Додаткова проблема $з$ точки теорії відцентрового розвантаження виникає за рахунок того, що верхній привідний вал з зірочкою приводу ланцюга зі скребками та підшипниковими вузлами має змогу зміщуватись відносно кришки верх- ньої частини зернового елеватора (рис. 3 , поз. 1) у вертикальному напрямі за допомогою дії важелів системи механізму натягування ланцюга зі скребками (рис. 3, поз. 2, 3).

В такому технічному виконанні (рис. 3) між верхньою кромкою скребка та кришкою верхньої частини зернового елеватора утворюється додатковий, досить суттєвий зазор, що сприяє збільшенню кута зворотного сипу $\beta$ (рис. 2). Такий зазор зменшується по мірі розтягування ланцюга зі скребками.

Для усунення вищеперерахованого недоліку нами запропоновано дообладнати верхню частину скребкового елеватора додатковим рухомим в системі механізму натягування кожухом, що компенсує появу вищеописаної проблеми з зазором між скребками та верхньою кришкою елеватора. 


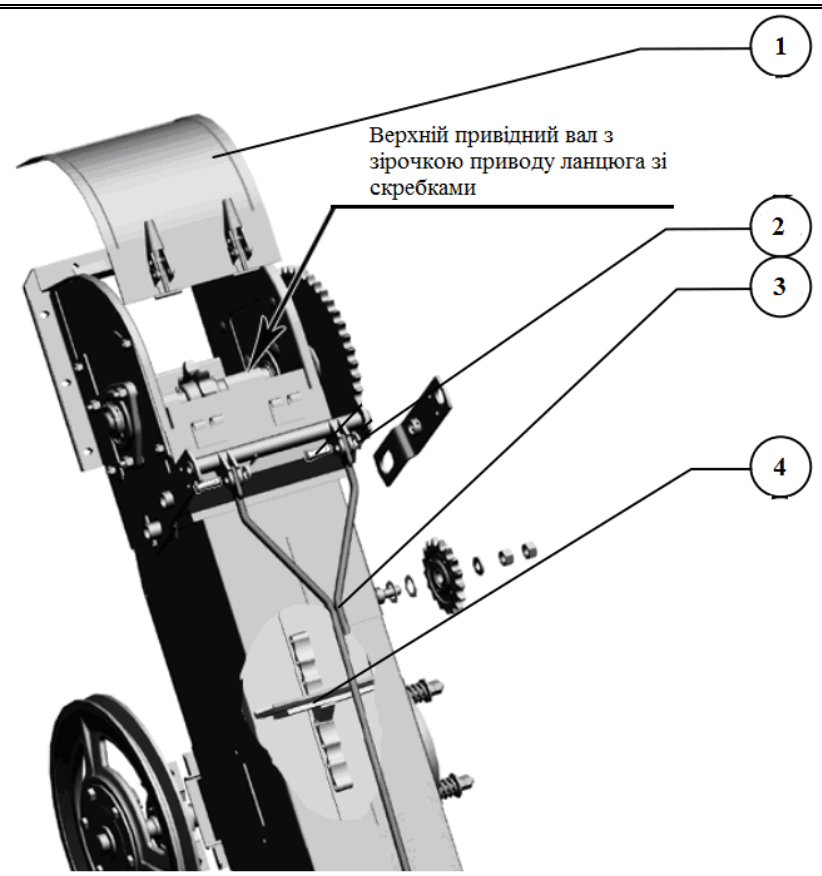

Рис. 3. Верхня частина скребкового елеватора зернозбирального комбайна типу «Славутич», «Дон», «Вектор», «Акрос»

1 - кришка верхньої частини зернового елеватора; 2 - система важелів натяжного механізму ланцюга зі скребками; 3 - натяжна тяга; 4 - частина ланцюга зі скребком в зоні транспортування зерна.

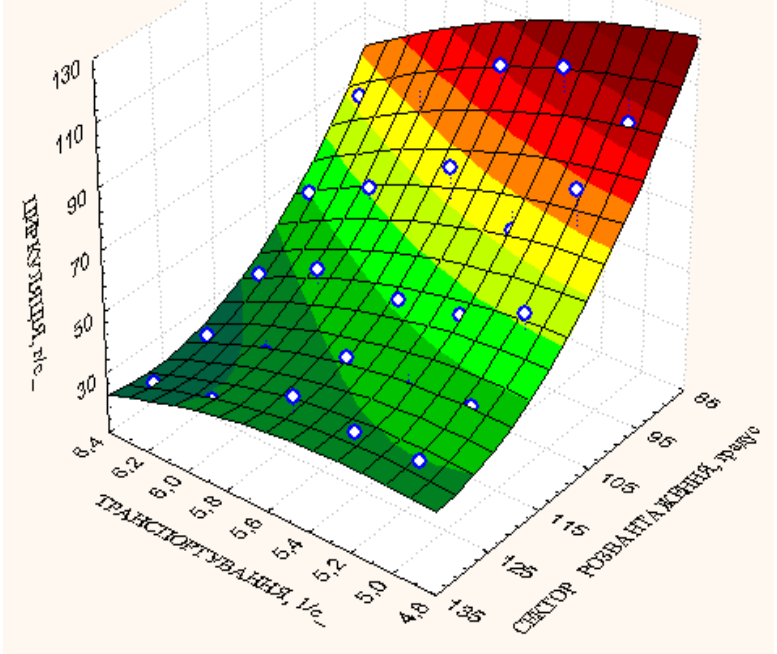

Рис. 4. Квадратична поверхня відгуку зворотного сипу (колової циркуляції Z) від швидкості транспортування та сектору розвантаження під час транспортування озимої пшениці

Наступною частиною дослідження по пошуку шляхів покращення відцентрового розвантаження у скребковому елеваторі є оптимізація величини сектору розвантаження. Для вирішення такого завдання нами було проведено ряд досліджень за допомогою спеціальної експериментальної установки $[1,2,3,4]$. Сектор зони розвантаження можливо змінювати за допомогою зміни висоти зони розвантаження (рис. 2).
Швидкість транспортування зерна змінювалась за допомогою зміни обертів привідного валу з зірочкою приводу ланцюга зі скребками (рис. 3).

Приклад отриманих поверхонь відгуку другого порядку, як залежностей зворотного сипу (колової циркуляції) від швидкості транспортування та сектору розвантаження наведено на рис. 4 та рис. 5. 


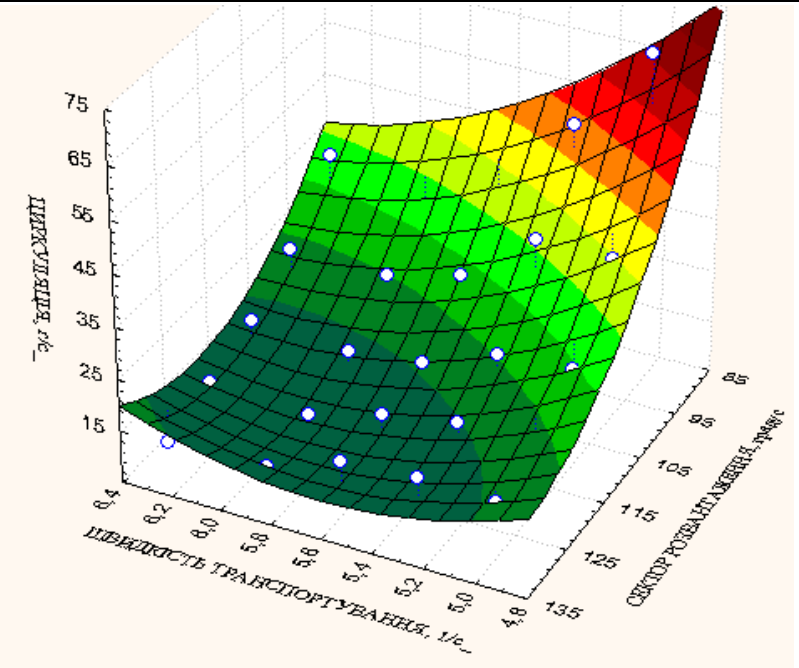

\section{Рис. 5. Квадратична поверхня відгуку зворотного сипу (колової циркуляції Z) від швидкості транспортування та сектору розвантаження під час транспортування кукурудзи}

Аналізуючи поверхні відгуку другого порядку, що подані на рис. 4 та рис. 5, можна зазначити, що зменшення зворотного сипу зерна в скребковому елеваторі під час відцентрового розвантаження можливо здійснити за рахунок збільшення сектору розвантаження до $140 €$ та швидкості транспортування до 360 об./хв.

Також за результатами експерименту проведено вимірювання енергетичних параметрів транспортування зерна скребковим елеватором, при цьому встановлено, що зменшення колової циркуляції в елеваторі з 7-10\% до 2$3 \%$ від загальної подачі зерна дає можливість заощадити 0,075-0,085 кВт енергетичних витрат на транспортування в разі продуктивності елеватора 5-5,5 кг/с.

\section{Висновки:}

1. У технічному виконанні скребкових елеваторів зернозбиральних комбайнів модельного ряду «Славутич», «Дон», «Вектор», «Акрос»- як наслідок конструктивної особливості натяжного механізму ланцюга зі скребками - між верхньою кромкою скребка та кришкою верхньої частини

\section{БІБЛІОГРАФІЯ}

1. Патент на корисну модель: №41504, Україна, МПК (2009) A01D 41/00. Установка для дослідження технологічних процесів елеватора комбайна / заявлений 22.12.2008; опубл. 25.05.2009, бюл. №10. Винахідники: Бурлака О. А., Слинько О. П., Бурлака О. П., Сосновська О. О., Прасолов С. Я., К Костоглод К. Д., Браженко С. А.; Винахідники та власники: Бурлака О.А., Слинько О. П.

2. Патент на корисну модель: №41557, Україна, МПК (2009) A01D41/00. Спосіб дослідження зернового елеватора утворюється додатковий, досить суттєвий зазор, що сприяє збільшенню кута зворотного сипу $\beta$. Для усунення такого недоліку нами пропоновано встановлення у верхній частині скребкового елеватора додаткового направляючого кожуха.

За результатами експериментальних досліджень по якості відцентрового розвантаження скребкових елеваторів зернозбиральних комбайнів модельного ряду «Славутич», «Дон», «Вектор», «Акрос» встановлено, що покращення умов роботи елеватора в діапазоні зміни швидкості транспортування від 300 до 360 об./хв. збільшення сектору розвантаження до $140 €$ та обладнання верхньої частини додатковим направляючим кожухом для врахування дії натяжного механізму.

2. Встановлено, що зменшення колової циркуляції в елеваторі з 7-10\% до 2-3 \% від загальної подачі зерна дає можливість заощадити $0,075-$ 0,085 кВт енергетичних витрат на транспортування при продуктивності елеватора 5-5,5 кг/с.

технологічних процесів / заявлений 29.12.2008; опубл.25.05.2009, бюл. №10. Винахідники: Бурлака О. А., Слинько О. П., Бурлака О. П., Сосновська О.О., Прасолов Є. Я., Костоглод К. Д., Браженко С. А.; Винахідники та власники: Бурлака О.А., Слинько О.П.

3. Патент на винахід: № 91783 Україна, МПК(2009) A01D 61/00, A01D 93/00. Установка для дослідження технологічних процесів елеватора комбайна / номер заявки: а 2009 01515, дата подання заявки Установка для дослідження тех- 


\section{ТЕХНІЧНІ НАУКИ}

нологічних процесів елеватора комбайна /: 23.02.2009; опубл. 25.08.2010, бюл. №16. Винахідники: Бурлака О. А., Слинько О. П., Бурлака О. П., Сосновська О.О., Прасолов С. Я., Костоглод К. Д., Браженко С. А.; Винахідники та власники: Бурлака О.А., Слинько О.П.

4. Бурлака О. А. Дослідження технологічного

\section{ANNOTATION}

Burlaka O. A., Yakhin S. V. The increase of working efficiency of scraper elevators with centrifugal unloading.

When transporting grain, the return fall and, respectively, partial crushing of grain by scrapers, a chain and asterisks of an elevator are observed. It is because of detected imperfection of an elevator's head design combined with a tension device

The correction of a trajectory of a grain flow is carried out by a cover of an upper part of an elevator.

If the time of the movement of grain on an elevator scraper surface is equal or smaller than the time of rotation of a scraper when passing a zone of unloading, then we have a high probability of hit of layers of a grain flow in necessary limits, at the same time centrifugal unloading is successfully.

If the trajectory of grain layers gets to a lower zone, then there is a possibility of grain entering in a single part of a scraper elevator that is, the return rash, circular circulation of grain in an elevator casing, is formed.

Such phenomenon is negative as it involves additional power costs of transportation; increases crushing and compression damage of grain weight, accelerates wear of operating parts of the grain transport system of the combine.

The next part of the research, devoted to the ways процесу розвантаження та обгрунтування параметрів підйомного елеватора зернозбирального комбайна: Дис. канд. техн. наук: 05.20.01 / УААН; Інститут механізації та електрифікації сільського господарства УААН (IMЕСГ УААН). - К., 2000. - 239 арк. + дод.

of improvement of centrifugal unloading in a scraper elevator, is optimization of size of the sector of unloading. For the solution of such task we have conducted a number of researches by means of special experimental installation. It is possible to change the sector of a zone of unloading by means of change of height of unloading zone. Speed of transportation of grain was different with the change of turns of a power shaft with an asterisk to a chain occasion with scrapers.

According to the result of the experiment measurement of power parameters of grain transportation by a scraper elevator is taken, at the same time it is found out that reduction of circular circulation in an elevator from $7-10 \%$ to $2-3 \%$ of the general supply of grain gives the chance to save $0,075-0,085 \mathrm{~kW}$ of power costs of transportation with a productivity of elevator of $5-5,5 \mathrm{~kg} / \mathrm{s}$. To eliminate this drawback, it is proposed to install an of the additional directing casing in the upper part of the scraper elevator of the additional directing casing.

To eliminate this drawback, it is proposed to install an additional directing body in the upper part of the scraper elevator.

Keywords: elevator, grain flow, grain crushing, sector of unloading, circular circulation. 